\title{
Trabalhando pelos bons vinculamentos: Reflexões antropológicas sobre o ofício das doulas
}

Working for create good bonds. Anthropological reflections on the doulas craft

\section{Giovana Acacia Tempesta}

\section{(2) OpenEdition}

12 Journals

Edição electrónica

URL: http://journals.openedition.org/aa/2784

DOI: $10.4000 /$ aa. 2784

ISSN: 2357-738X

Editora

Programa de Pós-Graduação em Antropologia Social (UnB)

\section{Edição impressa}

Data de publição: 1 julho 2018

Paginação: 37-66

ISSN: 0102-4302

\section{Refêrencia eletrónica}

Giovana Acacia Tempesta, «Trabalhando pelos bons vinculamentos: Reflexões antropológicas sobre o ofício das doulas», Anuário Antropológico [Online], v.43 n.1 | 2018, posto online no dia 26 maio 2019, consultado o 27 abril 2021. URL: http://journals.openedition.org/aa/2784 ; DOI: https://doi.org/ 10.4000/aa. 2784

\section{(c) (i) (9)}

Anuário Antropológico is licensed under a Creative Commons Atribuição-Uso Não-Comercial-Proibição de realização de Obras Derivadas 4.0 International. 


\title{
Trabalhando pelos bons vinculamentos: reflexões antropológicas sobre o ofício das doulas
}

\author{
Giovana Acacia Tempesta \\ Antropóloga independente
}

\section{Introdução}

O presente artigo versa sobre um aspecto central do trabalho realizado pelas doulas e educadoras perinatais ${ }^{1}$ - mulheres que apoiam mulheres durante a gestação, o parto e o puerpério -, qual seja, a habilidade de estabelecer e sustentar uma modalidade específica de vinculamento. ${ }^{2}$

No Brasil, as doulas desempenham papel relevante no movimento conhecido como "humanização" do parto e do nascimento, ideário que conheci no ano de 2014, quando engravidei. Nas primeiras semanas de gestação, optei por contratar uma doula, comecei a estudar sobre parto humanizado e medicina baseada em evidências científicas atualizadas e passei a fazer parte de grupos virtuais de debate sobre parto "normal".

O movimento de "humanização" do parto e do nascimento se expressa etnograficamente em formas variadas e interconectadas, a saber: uma grande quantidade de blogs e grupos virtuais na internet voltados para a gestação, o parto e o puerpério; edição de leis e normativas referentes à atenção à saúde da mulher durante a gestação, o parto e o pós-parto; produção de documentários e exposições; realização de fóruns e conferências nacionais e internacionais; veiculação de reportagens pelos meios de comunicação de massa e formação de grupos presenciais de apoio a mulheres gestantes e puérperas. Trata-se, em linhas gerais, de uma modalidade de ativismo de mulheres empenhadas em assegurar o direito de parir de forma respeitosa e satisfatória, com o menor número possível de intervenções obstétricas consideradas invasivas.

$\mathrm{Na}$ fase inicial da pesquisa, minhas interlocutoras principais são doulas e educadoras perinatais que residem e atuam em Brasília (DF). São mulheres nas faixas etárias de 20 a 50 anos, formadas em diversas áreas do conhecimento, com modos de se apresentar e de atuar bastante variados, que afirmam estar alinhadas à Medicina Baseada em Evidências científicas atualizadas (ou "MBE”), que se apropriam de forma crítica dos preceitos da "humanização" e que estão ou estiveram até muito recentemente engajadas em ações voltadas à regula- 
mentação da profissão e à formação de doulas em Brasília, e também em outras cidades do país. Fui apresentada a elas por uma parteira que eu conhecera anos antes e a quem eu expliquei os contornos da pesquisa que eu tinha em mente.

No presente artigo, recupero falas emblemáticas proferidas por cinco doulas - Gorete, Marina, Mônica, Sharon e Sônia -, registradas durante a fase de elaboração do desenho metodológico da pesquisa, quando estive com elas em eventos públicos e em encontros destinados somente a doulas, todos em Brasília, quando tivemos conversas informais e participamos de grupos sobre parto e doulagem nas redes sociais. Os eventos e encontros são os seguintes: i. audiência pública sobre a Lei n. ${ }^{\circ}$ 5.534/2015 ("Lei do Parto Humanizado no DF"), na Câmara Legislativa, em 11 de novembro de 2016; ii. IV Conferência Internacional sobre Humanização do Parto e Nascimento: Acolhendo experiências e irradiando mudanças, entre 26 e 30 de novembro de 2016; iii. I Fórum Internacional de Doulas, realizado como atividade independente no bojo da IV Conferência, em 27 de novembro; iv. aula inaugural do $1 .{ }^{\circ}$ curso de formação doulas, ministrado como curso de extensão no âmbito de uma instituição pública brasiliense, em 15 de dezembro de 2016, em parceria com a Associação de Doulas do Distrito Federal; v. lançamento oficial do documentário Sem hora para chegar: a busca pelo parto humanizado no Distrito Federal, na Faculdade de Ciências da Saúde da UnB, seguido de debate, em 08 de junho de 2017. Uma vez consolidado o desenho metodológico, iniciei a pesquisa propriamente dita por meio da participação em um curso intensivo ${ }^{4}$ de formação de doula e educadora perinatal, em setembro de 2017. Posteriormente, realizei entrevistas estruturadas com as cinco doulas citadas. ${ }^{5}$

Em todas essas ocasiões, eu me apresentei como pesquisadora e, em algumas situações, me senti interpelada a compartilhar minha experiência pessoal de gestação, parto e puerpério, mediada por doulas, bem como a esclarecer detalhadamente a minha motivação para a pesquisa. Aos poucos percebi que há uma grande diversidade de estilos de doulagem, desde abordagens mais tradicionalistas (como as "doulas na tradição", que trabalham com parteiras tradicionais) até abordagens bastante tecnicistas (que se aproximam da enfermagem obstétrica), incluindo aquelas que mesclam técnicas ${ }^{6}$ e concepções gestadas no âmbito de distintas matrizes epistemológicas. No interior deste universo multifacetado, optei por iniciar a pesquisa pela vertente que me pareceu mais interessante para refletir criticamente sobre o binarismo Natureza-Cultura, qual seja, a das doulas alinhadas à MBE. 


\section{Contextualizando a problemática da pesquisa}

O movimento de "humanização" do parto e do nascimento no Brasil integra um movimento mais amplo na área da saúde, organizado em torno da valorização da intersubjetividade nas relações, cujas repercussões se fazem sentir desde os anos 1980 (cf. Minayo, 2006:26). No que se refere especificamente à assistência ao parto e ao nascimento, as "estruturas centrais do processo de humanização" concernem ao respeito à fisiologia do trabalho de parto, à garantia da presença de acompanhante da escolha da mulher, ao respeito aos desejos da mulher no momento do parto e à criação de um ambiente propício para que ela seja tratada como protagonista do parto (cf. Deslandes, 2006:360).

Para Simone Diniz: “A humanização aparece como a necessária redefinição das relações humanas na assistência, como revisão do projeto de cuidado, e mesmo da compreensão da condição humana e de direitos humanos" (Diniz, 2005:631-2). Esse processo de "humanização" do parto e do nascimento abrange múltiplas nuanças, perspectivas e contradições internas. Essa autora indica que os vários sentidos do termo correspondem a reivindicações de legitimidade do discurso, explicitando que "humanização é também um termo estratégico, menos acusatório, para dialogar com os profissionais de saúde sobre a violência institucional" (idem, ibidem: 635).

Assim, os enunciados "humanizados" - que podem ser lidos em blogs e comunidades virtuais, tais como Amigas do Parto, Parto do Princípio e O Renascimento do Parto 2, o Filme ${ }^{7}$ - emergem como contraponto à crescente "medicalização" da sociedade brasileira e, por vezes, são entendidos pelos profissionais da saúde e por leigos alinhados com os preceitos da biomedicina como primitivistas ou como um modismo elitista. A decisão de algumas mulheres por recusar veementemente a cesárea eletiva ou os medicamentos analgésicos durante o parto vaginal, por exemplo, por vezes é classificada negativamente como coisa de "índia", hipster ou "inconsequente". Nesse campo simbólico, a experiência da "dor do parto" aparece como divisor de águas entre as mulheres que desejam evitá-la e as mulheres que optam por experimentá-la. Acusações ainda mais duras recaem sobre mulheres que escolhem ter um parto domiciliar planejado, experiência forte em termos de "empoderamento" feminino no universo da "humanização".

Pesquisas antropológicas realizadas no século XXI (Carmen Susana Tornquist, 2004; Heloisa Regina Souza, 2005; Olivia Hirsch, 2014; Mariana Marques 
Pulhez, 2015; Rosamaria Giatti Carneiro, 2015; Laís Oliveira Rodrigues, 2015; Mariana Portella, 2017) demonstram os desdobramentos sociológicos, políticos, culturais, éticos, estéticos e existenciais implicados na conduta de mulheres que, na condição de gestantes, parturientes e puérperas, reivindicam o direito de tomar decisões sobre a gravidez, o parto, o puerpério e os cuidados com o recém-nascido, e desejam adensar os sentidos que conformam sua experiência pessoal.

Algumas pesquisadoras sustentam que o movimento de humanização do parto e do nascimento consiste em uma “organização paradigmática que se pauta tanto no modelo biomédico, através da Medicina Baseada em Evidências, quanto na abertura epistemológica para diversas práticas oriundas de outros sistemas de cura" (Pimentel et. al., 2014:168). Nesses termos, o protagonismo da mulher gestante requer acesso à informação de qualidade sobre a fisiologia do parto e sobre o contexto do atendimento obstétrico (idem: 175), desafiando-se, assim, a lógica colonial característica do paradigma biomédico, que engendra a violência obstétrica (idem: 183).

Esse breve levantamento bibliográfico indica que o fenômeno social em pauta expressa a configuração de uma nova sensibilidade e consciência social em torno das experiências de gestação, parto, nascimento e puerpério, que está sendo delineada no seio de um segmento social específico, composto predominantemente por mulheres escolarizadas, de camadas médias urbanas. Observa-se, ainda, que certos conceitos, imagens ${ }^{8}$ e afetos explicitados no interior desse campo de forças desestabilizam, em alguma medida, a hegemonia dos valores sociais que sustentam os protocolos adotados pelas instituições médico-hospitalares.

Antes de prosseguir, considero relevante esclarecer a opção teórico-metodológica pelo conceito de "experiência", em detrimento de outros conceitos possíveis, para delimitar as situações de gestação, parto e puerpério, bem como a relação entre doula e doulanda. Trata-se de uma aproximação com a obra da antropóloga Cheryl Mattingly (2014), que entende a dimensão da experiência vivida nos termos de uma "ética em primeira pessoa", que se realiza em um self relacional e temporal, aberto para a contingência. A autora propõe que os experimentos de cuidado conduzidos em diferentes "laboratórios morais" (o hospital, a casa, a igreja, a escola, a rua) implicam "negociação, problematização e, por vezes, confronto com as instituições e seu modo especializado de cuidado ou com os modos de cuidado característicos da vida comunitária cotidiana”, o que possibilita pequenas, mas significativas, revoluções na esfera do cotidiano 
(Tempesta, 2017:651). Dos espaços de conversação sobre os problemas enfrentados pelas pessoas emergem, então, formas outras de lidar com a ideia de risco, associadas a um conceito de saúde que se amplia em direção a variados ideais de bem viver.

Em minha conversação com as citadas doulas, observo que elas mobilizam, de uma forma particularmente interessante, aspectos centrais dessa nova sensibilidade e consciência social, relacionados à experiência do parto respeitoso. A partir de dados etnográficos preliminares, proponho que, ao contratar os serviços de uma doula, mulheres grávidas que desejam e dispõem de condições objetivas para viver a gestação, o parto e o puerpério como experiências fortes de realização pessoal - algo que lhes seria negado pelo sistema médico-hospitalar - estariam buscando um tipo de apoio bastante singular, que extrapolaria as tendências liberais, individualistas e hedonistas presentes no ideário da "humanização" do parto.

Ao focalizar a dimensão do vinculamento sob a perspectiva crítica formulada por Bruno Latour (2016), ${ }^{9}$ avanço a hipótese de que as atitudes e sentimentos de mulheres em relação a tais experiências têm gerado alterações concretas em várias esferas da vida social e nos modos de subjetivação feminina. Tal perspectiva pode nos levar a vislumbrar os contornos de uma "linha de fuga" (nos termos de Gilles Deleuze apud Agamben, 2016:19) ${ }^{10}$ no interior do sistema capitalista de produção e reprodução de pessoas, contra a qual são dirigidas acusações inflamadas por diversos atores sociais alinhados com os preceitos da biomedicina, entendida como dispositivo de controle dos corpos.

O propósito mais geral é, portanto, compreender como "as múltiplas pequenas escolhas cativas nos laços” (cf. Latour, 2016:75) estabelecidos por adeptas do parto "humanizado" e doulas vêm contribuindo, na virada para o século XXI, para problematizar, tensionar e desestabilizar conceitos e imagens concernentes à gestação, ao parto e ao puerpério que se cristalizaram no senso comum, dentro e fora do sistema médico-hospitalar.

O ideário da "humanização" do parto tem diversos pontos de contato com o ideário do "casal grávido", tributário da ideologia individualista (em termos dumontianos) e libertária, vigente nos anos 1980 entre camadas médias urbanas brasileiras, que foi analisado por Tania Salem (2007). Dentre eles, vale destacar a tendência a afastar a mãe da parturiente da cena de parto e a "medicalização de segundo grau" (aqui expressa no recurso à MBE). Todavia, não se observa, 
na fala de minhas interlocutoras, a pertinência da ética da indiferenciação de gênero que caracterizou esse código moral; ao contrário, aqui a ênfase recai sobre a valorização da experiência da mulher.

Neste sentido, desejo tomar parte nos debates sobre um aspecto importante do trabalho das doulas e, de uma forma mais ampla, do ideário sustentado pelo movimento da "humanização", que foi interpretado como contradição por Soraya Fleischer (2005) e como armadilha por Carmen Susana Tornquist (2002, 2004), interpretações que eu resumiria nos termos do contrassenso de uma pedagogia do instinto feminino. Dito de outra maneira, essas autoras estão questionando a razoabilidade ou explicitando os riscos políticos e epistemológicos de um ideário que consiste na proposição de uma forma outra de viver as experiências de gestação, parto e puerpério.

Por seu turno, ao dialogar com Tornquist a respeito do significado do adjetivo “natural”, muitas vezes equiparado ao parto "humanizado", Rosamaria Carneiro $(2014,2015)$ sustenta que este termo pode ser analisado não sob a perspectiva de uma dicotomia rígida, que supõe uma hierarquia (a natureza subordinada à cultura), mas, assim como formulado por Roy Wagner, como resultado de um jogo entre convenção e invenção linguística, o que permite apreender a interface entre agenciamento e estruturação. O parto "mais natural", como escreve esta autora, abrange um amplo leque de práticas de parto e leituras da natureza que se situam entre o parto domiciliar planejado, de um lado, e a cesárea eletiva, de outro. ${ }^{11}$

De minha parte, inspirada pelas ideias de C. Mattingly, B. Latour e G. Agamben, estou propondo que o foco analítico na figura da doula e educadora perinatal nos ajuda a ampliar a visão sobre o ideário da "humanização" do parto desenhada pelas autoras mencionadas. De um modo geral, nas pesquisas citadas desponta um ideal de parto entendido como experiência "mais natural" e mais satisfatória para a mulher, porém em minha conversação com as doulas percebo uma ênfase na relação que elas estabelecem com as clientes também antes e depois do parto. Assim, se Tornquist identificou uma inversão de sinais na concepção dicotômica Natureza-Cultura e a construção de uma nova normatividade que viria a relegar as mulheres ao domínio simbólico da Natureza, o que minhas interlocutoras têm me mostrado, de forma pulsante, é a riqueza existente no "entremeio" dessa dicotomia, levando-me a formular a pergunta sobre o que essa contradição formal está produzindo no contexto estudado. Claro está que 
não se trata de romantizar um determinado ideário, mas de circunscrever o universo etnográfico pesquisado de forma positiva, de reconstituí-lo analiticamente em sua riqueza e complexidade, em suas muitas nuanças, olhando tanto para suas limitações intrínsecas quanto para suas potencialidades ainda não realizadas.

\section{“Humanizando" práticas, leis e informações científicas}

Em linhas gerais, o movimento do "parto humanizado" questiona de maneira contundente os constrangimentos colocados pelas instituições para as experiências de gestação, parto, nascimento e puerpério, além de chamar a atenção da opinião pública sobre os efeitos danosos da "cultura da cesariana" e de algumas práticas médicas rotineiras para a saúde e a integridade da mãe e do bebê, valendo-se de dados providos pela MBE, os quais são acolhidos e difundidos por organismos de saúde em níveis nacional e internacional, sobretudo pela Organização Mundial de Saúde (OMS). ${ }^{12}$

O desejo publicizado pelas ativistas da "humanização" do parto, em meio a um contexto de altas taxas de óbito materno e complicações de saúde relacionadas à medicalização considerada excessiva dessa experiência, consiste fundamentalmente em "se apropriar" das experiências de gestação e parto, usufruindo das tecnologias disponíveis de maneira criteriosa, parcimoniosa, informada e consentida, em prol de sua própria saúde e bem-estar. Segundo as ativistas, é preciso mudar a conduta dos profissionais, tanto no sistema público como no sistema suplementar de atenção à saúde, conduta esta imbricada no universo simbólico historicamente constituído em torno do parto, daí a importância de problematizar ideias e imagens naturalizadas pelos atores.

De outro modo, a prática da doulagem muitas vezes é compreendida nos termos da sororidade. ${ }^{13}$ Assim, as doulas estimulam a participação da mulher gestante ou puérpera em rodas de conversas presenciais e em espaços virtuais voltados para o ciclo gravídico-puerperal; a sua familiarização com relatos, fotos e vídeos de parto respeitoso; a redação e a divulgação de seu próprio relato de parto; e até mesmo a formação dessa mulher (doulanda) como doula. Nesta chave, o empoderamento decorrente do parto é considerado "um caminho sem volta", que contém uma força de contágio, conceituada como tomada de consciência de si face à hegemonia do modelo biomédico.

As doulas atuam no sentido de favorecer uma experiência de parto percebida como respeitosa, satisfatória, bonita, na qual os recursos médicos sejam 
empregados somente em caso de necessidade "real", e com o consentimento expresso da mulher. Assim, para que o parto seja considerado bem-sucedido, a parturiente deve ser respeitada em sua integralidade, enquanto protagonista do evento; ela deve receber todas as informações relevantes em linguagem compreensível e deve ser plenamente acolhida pelos presentes; seus ritmos fisiológicos e psicológicos únicos devem ser respeitados; a dor deve ser enfrentada da maneira que lhe convier no momento de sua manifestação; o contato pele a pele com o bebê deve ser estimulado; métodos não-farmacológicos devem ser aplicados para alívio do desconforto e das dores; e o laço com as pessoas significativas para ela deve ser resguardado na cena do parto.

Uma reivindicação central das ativistas da "humanização" perante o Estado brasileiro é a disponibilização de meios institucionais e legais para assegurar que o parto possa acontecer de modo seguro, respeitoso e satisfatório para a mulher, seja em ambiente hospitalar, seja em ambiente doméstico. Um desses meios é o Plano de Parto, documento protocolado junto à unidade de saúde quando da admissão da mulher para o parto, no qual são registradas as intervenções que a mulher aceita e sob quais circunstâncias, a possibilidade de ingerir alimentos e líquidos durante o trabalho de parto, a presença do acompanhante e da doula, a exigência de ser informada e consultada sobre todos os procedimentos a serem realizados, dentre outras informações pertinentes. Observa-se, pois, que um desejo surgido no seio de um segmento social específico vem se transformando em uma necessidade de saúde e em uma pauta de direitos humanos, configurando-se como uma luta pela transformação da cultura da assistência ao parto no Brasil. ${ }^{14}$

Defensoras do parto "humanizado" afirmam com frequência que estão "lutando contra o sistema" e se engajam em ações visando à transformação das bases do modelo de atenção obstétrica. Minhas interlocutoras doulas dizem que é muito difícil "lutar contra o sistema" sozinha, daí a importância de se vincular a um coletivo, presencial ou virtual. Um exemplo importante da politização do desejo de ter um parto mais respeitoso é a iniciativa da Associação de Doulas do Distrito Federal que, em 2016, apresentou na Câmara Legislativa uma minuta de projeto de lei que dispõe sobre medidas de combate à violência obstétrica.

Em sua "luta contra o sistema", as doulas com as quais dialogo se valem de informações disponíveis na Plataforma Cochrane, providas pela MBE, um modelo de cuidado baseado no emprego criterioso das provas científicas mais recentes para a tomada de decisões em relação a cada paciente, segundo o qual 
o médico valoriza a decisão compartilhada com o paciente (cf. Straus \& McAlister, 2000). Este é um movimento no interior do campo da medicina que se iniciou nos anos 1990 e que teve uma inspiração "fortemente questionadora, evidenciando as contradições e a distância entre as evidências sobre efetividade e segurança, e a organização das práticas [médicas correntes]", em nome da defesa dos direitos dos pacientes, bem como o peso do poder econômico e corporativo na definição das políticas e no desenho e financiamento das pesquisas na área da saúde (Diniz, 2005:630). Diniz menciona ainda o "processo de interfecundação conceitual, não sem contradições, que se deu por meio da participação das usuárias e ativistas no desenho e disseminação das pesquisas" (idem, ibidem: 633).

O recurso à MBE e a sensibilização para a riqueza simbólica e a complexidade existencial da experiência do parto e do nascimento podem ser interpretados como táticas empregadas pelas doulas com o objetivo de construir ou fortalecer um outro tipo de "conhecimento autoritativo"15, isto é, de validar um outro corpo de conhecimento a partir de um certo tipo de autoridade, que implica outra linguagem, outra modalidade de tecnologia e outro modelo de relação para circunscrever as experiências de gestação, parto e puerpério. Tal modelo alternativo de assistência ao parto fundamenta-se em um princípio holístico, que implica a aceitação daquilo que não pode ser controlado ou conformado a padrões universais, classificado neste universo como um elemento feminino. Observa-se, portanto, para além da contradição identificada por Fleischer (2005) e da armadilha identificada por Tornquist (2002), um embaralhamento de fronteiras entre elementos comumente atribuídos de forma estanque aos domínios simbólicos da Natureza e da Cultura.

A partir das palavras preliminares de minhas interlocutoras, percebo que tal embaralhamento não assume a forma de uma colisão frontal ou do conflito aberto com o sistema médico-hospitalar, mas, sim, a forma de uma dança, que interpreto como uma "linha de fuga", uma tomada de posição nos interstícios da dualidade "tradicional” /“pós-moderno”, uma política em primeira pessoa que se constitui em torno da "experiência que fazemos todos os dias ao estar em contato com uma potência impessoal, algo que, ao mesmo tempo, nos ultrapassa e nos faz viver" (Agamben, 2016:29).

Ao indicar fontes de informações atualizadas e confiáveis, ao oferecer apoio emocional e ao aplicar técnicas não-invasivas de controle da dor e amenização dos desconfortos, selecionadas a partir da percepção sobre as necessidades espe- 
cíficas de cada mulher, as doulas alinhadas à MBE parecem estar explicitando, reversamente, o contrassenso inerente aos enunciados biomédicos sobre o caráter supostamente não-mediado, "natural”, instintivo e automático das experiências de gestação, parto e pós-parto. Elas estariam, assim, avançando uma pauta cultural com repercussões importantes em nível macrossociológico, sintetizada na categoria analítica de "apoio", que tensiona o conceito de "cuidado", sobre o qual se estruturam os enunciados em circulação no campo da saúde coletiva. Um exemplo importante desse alcance mais amplo me foi dado pela doula Marina, que já trabalhou como instrutora do curso de formação a que assisti em 2017, e que esclareceu que a grande maioria das mulheres em trabalho de parto solicita analgesia devido ao medo da dor, não à dor propriamente; ela se refere à dor de parto como um "mito" da sociedade contemporânea que deve ser desconstruído pelas mulheres. ${ }^{16}$

\section{Sobre modelos e condutas}

Com base naquilo que foi apresentado até aqui, pode-se inferir que estamos diante de uma questão eminentemente cultural, concernente a relações de gênero e poder, que ganha corpo na forma de um ideário que tensiona a lógica biomédica do controle da vida e da compartimentalização da pessoa. Nesses termos, pode-se afirmar que as adeptas do parto "humanizado", em geral, e as doulas, em particular, estão "colocando em jogo" (cf. Lefort, 1978) ${ }^{17}$ o sentido dominante de nascer no Brasil no século XXI.

Sugiro que os principais conceitos mobilizados por esse conjunto de doulas alinhadas à MBE podem ser alocados sob dois modelos distintos, chamados de "biomédico" e "humanizado", conforme se vê na tabela a seguir:

\begin{tabular}{|l|l|}
\hline Modelo biomédico & Modelo humanizado (respeitoso) \\
\hline $\begin{array}{l}\text { risco como variável a ser esquadrinhada } \\
\text { antes e durante o evento }\end{array}$ & risco como parte da vida \\
\hline $\begin{array}{l}\text { protagonismo da equipe } \\
\text { médica hierarquia rígida, } \\
\text { responsabilidades estanques }\end{array}$ & $\begin{array}{l}\text { protagonismo da mulher que } \\
\text { dá à luz relação simétrica, } \\
\text { responsabilidade compartilhada }\end{array}$ \\
\hline $\begin{array}{l}\text { informações especializadas como } \\
\text { monopólio do profissional }\end{array}$ & $\begin{array}{l}\text { informações especializadas compartilhadas } \\
\text { e debatidas com a mulher }\end{array}$ \\
\hline impessoalidade & empatia, conexão \\
\hline
\end{tabular}




\begin{tabular}{|l|l|}
\hline contato físico mediado por instrumentos & contato pele a pele \\
\hline ideal de assepsia completa & $\begin{array}{l}\text { aceitação do contato com substâncias } \\
\text { corporais (sangue, líquido amniótico, } \\
\text { suor, fezes) }\end{array}$ \\
\hline $\begin{array}{l}\text { dor como emoção a ser combatida } \\
\text { ou neutralizada }\end{array}$ & dor como emoção a ser acolhida \\
\hline $\begin{array}{l}\text { horários, medidas e padrões impostos pela } \\
\text { instituição ou pelos profissionais de saúde }\end{array}$ & $\begin{array}{l}\text { respeito aos ritmos fisiológicos e } \\
\text { psicológicos únicos da mulher, às suas } \\
\text { decisões e desejos }\end{array}$ \\
\hline $\begin{array}{l}\text { práticas generalizantes e objetificadoras das } \\
\text { pessoas }\end{array}$ & $\begin{array}{l}\text { práticas individualizadas que respeitam a } \\
\text { subjetividade da mulher }\end{array}$ \\
\hline $\begin{array}{l}\text { pessoa como portadora de um problema } \\
\text { (doença, desvio, imperfeição etc.) a ser } \\
\text { resolvido ou de uma imperfeição a ser } \\
\text { corrigida, normalizada }\end{array}$ & $\begin{array}{l}\text { pessoa como microcosmo de relações a } \\
\text { serem acolhidas }\end{array}$ \\
\hline $\begin{array}{l}\text { ideal de corpo imóvel, genérico, passível de } \\
\text { manipulação }\end{array}$ & $\begin{array}{l}\text { ideal de corpo em liberdade, investido de } \\
\text { emoções, desejos e sensações singulares }\end{array}$ \\
\hline $\begin{array}{l}\text { o resultado (bebê saudável) importa mais } \\
\text { que o processo (trabalho de parto) }\end{array}$ & $\begin{array}{l}\text { resultado e processo são } \\
\text { igualmente importantes }\end{array}$ \\
\hline $\begin{array}{l}\text { abordagem fragmentária e mecânica do } \\
\text { parto e do nascimento }\end{array}$ & $\begin{array}{l}\text { abordagem holística/orgânica do parto e do } \\
\text { nascimento }\end{array}$ \\
\hline tecnologia dura & tecnologia leve \\
\hline “moderno" & "mais natural” \\
\hline .. & \\
\hline
\end{tabular}

Tabela 1 - Modelos biomédico e humanizado de atenção ao parto

A tabela foi elaborada ao estilo estruturalista, de modo a subsidiar a análise não dos termos isolados, mas das relações que os unem e que formam um sistema de significados (Lévi-Strauss, 1970). A tabela é intencionalmente aberta e incompleta, sendo que a coluna da esquerda (modelo biomédico) foi preenchida a partir do discurso da "humanização" do parto; reversamente, os elementos que constam na coluna da direita (modelo humanizado) se constituem na contraposição aos elementos atribuídos ao modelo biomédico.

Nos estreitos limites do presente artigo, é suficiente reter o fato de que o modelo biomédico opera com as premissas racionalistas da partibilidade da pessoa (a mulher) e da fragmentação da experiência do parto, premissas igualmente presentes nos relatos das 165 mulheres norte-americanas entrevistadas 
pela antropóloga Emily Martin, nos anos 1980. Para esta autora, a fragmentação da mulher em trabalho de parto assume duas formas distintas e inter-relacionadas: a fragmentação do trabalho de parto em "fases" ou "estágios" rígidos, que podem ser traduzidos em números e controlados de perto por terceiros, e a fragmentação da unidade mãe-feto. De acordo com ela, trata-se de um processo histórico no interior do qual "foi construído para o médico o papel de se aliar ao bebê contra a destruição em potencial causada pelo corpo da mãe” (Martin, 2006:119-120). Este processo histórico corresponderia a um movimento de apagamento da mulher da cena do parto, quando os direitos do feto passam a sobrepujar os direitos da mulher, a partir de imagens depreciativas sobre o corpo feminino, resultando em seu repúdio completo na "linha de produção de bebês perfeitos" (Martin, 2006:227-232). É a este panorama que se contrapõe o movimento da "humanização" do parto e do nascimento, na virada para o século XXI.

\section{Afinal, o que faz uma doula?}

Nesta seção, pretendo discutir algumas implicações de quatro enunciados que condensam conceitos e imagens recorrentes nas narrativas de minhas interlocutoras:

"Nós, da Associação de Doulas do Distrito Federal, estamos fazendo uma série de oficinas sobre tecnologia leve nos hospitais. Nós explicamos o papel da doula, que não pretende ocupar o papel de outros profissionais, mas sim se somar à equipe." Sônia, representante da Associação de Doulas, no debate durante o lançamento oficial de um documentário sobre parto; $2017^{18}$

"As pessoas acham que a gente trabalha por amor, por isso não precisa receber dinheiro. Não estou dizendo que a gente não trabalha com amor, mas não podemos trabalhar só por amor.”. Mônica, durante a primeira conversa sobre minha proposta de pesquisa; 2016

"O mais importante é a gente se conectar com a mulher. A gente é capaz de fazer isso. A gente tem que saber qual é o nosso lugar no mundo e saber que ninguém pode tocar na gente se a gente não quiser. Tudo é conexão, é como na dança. É mágico." Gorete, coordenadora do curso de formação, na condução da roda de conversa sobre uma vivência realizada durante o curso; 2017

"Cuidar do outro é uma responsabilidade. É muito importante aprender a caminhar junto com outras mulheres." Sharon, monitora do curso, na mesma roda de conversa; 2017 
É importante ressalvar que a recorrência desses enunciados nas narrativas que circulam no interior do conjunto de doulas que venho acompanhando não é sinônimo de um discurso homogêneo, tampouco de uma coesão em termos de atuação profissional e militância. De outro modo, o que se observa em campo é uma grande profusão de estilos de doulagem, além da existência de pontos de vista divergentes sobre diversos temas afetos ao ofício, os quais, por vezes, podem se transformar em rivalidades e dar origem a conflitos.

A figura contemporânea da doula evoca a centralidade do papel historicamente desempenhado pelas mulheres nos assuntos concernentes à gravidez, ao parto e ao pós-parto, papel que se expressa no idioma do cuidado e que, no mundo ocidental, foi suplantado pelos homens somente em meados do século XX. Tal centralidade de gênero é destacada no universo da "humanização" do parto e do nascimento e constitui o ponto de partida de um livro escrito por uma doula pioneira da "humanização" no Brasil (Fadynha, 2011), bem como de diversas outras publicações no campo da antropologia do parto, sobretudo a coletânea organizada por Robbie Davis-Floyd e Carolyn Sargent (1997). Tal alteração nas relações de gênero, envolvendo a gestação, o parto e o puerpério corresponde à substituição, igualmente recente, do conceito de "cuidado" pelo de "cura" (cf. Deslandes, 2006:353), sendo este último conceito cada vez mais dependente de instituições hierarquizadas, da figura do médico, de equipamentos sofisticados, fármacos e hormônios sintéticos.

Nas instituições convencionais, tudo se passa como se a mulher em trabalho de parto enfrentasse um problema que pode ser resolvido de forma eficaz, mediante a utilização de tecnologia dura:

Ser levada em cadeira de rodas ou em uma maca como se estivesse doente, ser submetida a hidratação venosa que a 'liga' ao hospital, mostrando sua dependência, e todos os procedimentos praticados na assistência reforçam as ideias de que a mulher não é capaz de parir sem a tecnologia médica e de que seu corpo, sem esse controle, pode trazer riscos para o bebê. No hospital estarão protegidos, ela e o feto, pela tecnologia ali oferecida e reafirmada constantemente pela ideia de que o conhecimento médico é mais importante que seus saberes ou valores culturais (Davis-Floyd, 1994). (Deslandes, 2006:354-5)

Minhas interlocutoras afirmam que a doula é a única profissional que, durante o parto, olha para a mulher. Porém, se ressentem do fato de que a maioria das 
pessoas, incluindo os profissionais de saúde, ignoram a natureza de seu trabalho; além disso, não é incomum que as doulas sejam hostilizadas no interior da instituição médico-hospitalar. Simbolicamente, no momento do parto a doula está a meio caminho entre os familiares próximos da parturiente, de um lado, e a equipe médica, de outro, havendo certa ambivalência em sua posição estrutural, uma vez que ela ocupa um lugar estratégico para acessar as emoções mais profundas e as ações mais críticas envolvidas nos eventos que cercam a gestação, o parto e o puerpério. Minhas interlocutoras problematizam ainda o fato de que a hierarquia médico-hospitalar não prevê um lugar para a doula. ${ }^{19}$

Como esclareceu Sônia, a doula atua em conjunto com parteiras, enfermeiras obstétricas e médicos, tanto em ambiente hospitalar quanto no parto domiciliar, sendo que seu trabalho não substitui nenhuma dessas especialidades, mas as complementa. Várias doulas dizem que a maioria das pessoas não compreende o que elas fazem porque este é um trabalho difícil de definir, de materializar, de quantificar, de precificar (e talvez, igualmente, de institucionalizar), como sugere a definição "mulher que serve", tradução da palavra de origem grega empregada para apresentar o ofício aos leigos.

O estilo de atuação das doulas varia bastante e os preços praticados, a duração e a complexidade dos serviços apresentam significativa diversidade, mas, em linhas gerais, pode-se afirmar que a ocupação de doula é desempenhada por mulheres e voltada eminentemente para mulheres (ainda que, em muitos casos, a doula acabe apoiando também o/a companheiro/a, a mãe ou o pai da doulanda, com o objetivo de instruí-los sobre a melhor maneira de apoiar a mulher). A doula alinhada à MBE presta um serviço que eu classifico provisoriamente como intangível, que abrange um vasto repertório de recursos, tais como massagens, exercícios físicos e mentais, banhos terapêuticos, compressas, chás de ervas com propriedades medicinais, dentre outras técnicas e saberes relativamente simples e de baixo custo, além do conhecimento de fontes de informação confiáveis sobre múltiplos aspectos da gestação, do parto e do puerpério.

As doulas desenvolvem um vocabulário diferenciado, no qual abundam siglas emprestadas ao jargão médico e são contemplados aspectos fisiológicos do parto que costumam causar constrangimento aos leigos (como, por exemplo, o fato de que a mulher pode defecar ou vomitar durante o trabalho de parto). Elas demonstram preocupação com o significado social das palavras empregadas, como atestam, por exemplo, a opção deliberada pelo termo "mulher grávida", 
no lugar de "gestante", e a evitação de termos como "mãezinha", optando-se pelo uso do nome da mulher, de modo a impedir a identificação restritiva da mulher à experiência da gravidez, bem como sua infantilização.

A atuação da doula foi incluída na categoria de "tecnólogos e técnicos em terapias complementares e estéticas" da Classificação Brasileira de Ocupações do Ministério do Trabalho no ano de 2013. Trata-se de um serviço particular, prestado mediante contrato individual, cujo valor médio gira em torno de um salário mínimo e meio. Mas muitas doulas também trabalham como voluntárias em hospitais e maternidades públicas.

Entretanto, como percebemos na fala de Mônica, existe um dilema em torno da melhor maneira de profissionalizar essa modalidade de cuidado feminino, que se expressa por meio de questionamentos de amplo escopo, assim resumidos: como atribuir valor monetário a um serviço baseado na afetividade, que acolhe o imprevisível e o incontrolável da experiência humana? Como transformar um contrato de prestação de serviço em um bom vinculamento? Como estipular regras de validade geral para um tipo de serviço que assume formas tão diversificadas na prática? Podemos deduzir dessas contradições uma intenção declarada de revisar criticamente os componentes socioculturais e históricos do ofício, por meio da ênfase na distinção conceitual entre afeto e remuneração, explicitando-se que o desejo genuíno de apoiar outra mulher durante a gestação, o parto e o pós-parto é vivido como vocação profissional orientada politicamente, não como prática filantrópica.

Se o trabalho da doula não se confunde com o trabalho da parteira, da médica, da enfermeira obstetra, da técnica em enfermagem, da psicóloga, da fisioterapeuta ou da assistente social, por outro lado agrega, de forma singular, saberes e técnicas forjados em todas essas áreas de conhecimento e também em outras, de modo a proporcionar o acompanhamento personalizado da mulher gestante. Idealmente, ${ }^{20}$ durante a gestação, a doula escuta a cliente e dialoga com ela, de forma sensível e empática, a partir de informações atualizadas a respeito do ciclo gravídico-puerperal, e auxilia a doulanda a elaborar o Plano de Parto.

Conforme esclareceu Gorete, ao longo da progressão do trabalho de parto, a doula deve estar completamente disponível para apoiar a cliente com falas encorajadoras, olhar diferenciado, escuta ativa, massagens, técnicas de imposição de mãos, incentivo a vocalização, movimentos sobre bola de fisioterapia, estímulo a movimentos livres e organização harmônica do ambiente, os quais 
são adaptados às necessidades de cada doulanda, que é estimulada a seguir a sua intuição e o seu ritmo próprio. O momento mais delicado é chamado de "partolândia", que corresponde à "fase de transição", quando a mulher pode entrar em um estado alterado de consciência e ficar mais vulnerável a palavras e ações dos presentes na cena de parto. A doula pode ter contato direto com orifícios e substâncias corporais da parturiente e o corpo da profissional frequentemente funciona como instrumento para favorecer o desenrolar do trabalho de parto.

A doula é uma especialista em métodos não-farmacológicos de alívio das dores e desconfortos sentidos durante a gestação, o trabalho de parto (sobretudo as dores causadas pelas contrações uterinas) e o puerpério. Ela precisa ser capaz de avaliar qual o melhor recurso ou combinação de recursos para propor à mulher em cada situação particular. Para isso, ela se vale da habilidade para se conectar tanto com seu repertório de saberes, técnicas, sentimentos e objetos heteróclitos como com o ritmo dessa mulher em particular, acessando sua intuição para "balancear" necessidades e possibilidades, de modo semelhante ao que R. Davis-Floyd e E. Davis (1997) afirmam sobre as parteiras norte-americanas, que se orientam pelo sistema de conhecimento da intuição.

A doula não deve direcionar as atitudes de sua cliente, mas, sim, incentivá-la a tomar suas próprias decisões - ou "caminhar junto com ela", como disse Sharon. A doula desenvolve uma relação ímpar com a doulanda: "Escolher uma doula é como escolher um namorado. O santo tem que bater, senão o trabalho não dá certo", afirmaram algumas de minhas interlocutoras; dessa relação, elas extraem informações valiosas para modelar o atendimento adequado para cada situação. A delicadeza do trabalho de doulagem consiste na capacidade de interpretar corretamente os sinais emitidos pela doulanda, combinada à consciência sobre as próprias limitações profissionais e pessoais diante de algumas circunstâncias mais complexas, pois, assim como "cada parto é um parto", cada díade mãe-bebê é percebida como única e cada relação de doulagem é reputada singular. Ademais, a convicção sobre a aptidão natural da mulher e do bebê para o nascimento exprime-se nos enunciados: "Mulheres sabem parir, bebês sabem nascer" e "Nosso corpo foi feito para parir", recorrentes nos círculos "humanizados", embora sejam, por vezes, criticados por minhas interlocutoras.

O processo de "empoderamento" gradativo da mulher gestante apoiada pela doula favorece que ela desenvolva o senso crítico em relação não apenas ao universo biomédico, mas também a muitas ideias cristalizadas no senso comum no 
que concerne ao período gestacional, ao momento do parto, à amamentação, ao conjunto de cuidados dedicados ao recém-nascido e à experiência do puerpério. A doula pode desempenhar um papel importante também depois do parto, seja por meio de atendimentos individuais, seja por meio da coordenação de grupos presenciais e virtuais de apoio a mulheres no puerpério, incluindo o ensinamento de técnicas corporais, como a shantala (técnica de massagem em bebês), ou ainda apoiando a mulher no estabelecimento da amamentação. O resultado esperado da relação de doulagem é a mulher-mãe "empoderada”, que se sente segura para viver a experiência do parto à sua maneira, para enfrentar os desafios do puerpério e para tomar decisões “conscientes” em relação a sua própria saúde e à saúde do bebê.

\section{Sobre a formação das doulas alinhadas à MBE}

Assim que me dei conta de que estava diante de um repertório tecnológico específico, embebido num ideário contra-hegemônico e expresso numa modalidade de serviço ainda em vias de autonomização, minha atenção foi direcionada para a formação das doulas, um processo que já foi etnografado (Castelo, 2016) e também analisado em diálogo com o referencial teórico-metodológico da saúde coletiva (Loureiro, 2017).

De acordo com minhas interlocutoras, nenhum pré-requisito especial é considerado essencial para que uma mulher se torne doula, nem mesmo é necessário que ela seja ou deseje se tornar mãe, porém algumas características pessoais são bastante valorizadas, sobretudo a capacidade de empatia. Por outro lado, algumas das fontes de pesquisa indicadas nos cursos de formação exigem capacidade de assimilação de conceitos mais ou menos complexos das áreas de medicina, enfermagem, psicologia e antropologia, e há ainda artigos e livros em outras línguas (principalmente em inglês) apontados como importantes para a formação. ${ }^{21}$

Nas ocasiões aqui consideradas, minhas interlocutoras não usaram a definição "mulher que serve", preferindo falar em apoio ao "empoderamento" da mulher atendida. Além disso, elas questionam a centralidade que o evento do parto assumiu no interior do movimento da "humanização", em detrimento das fases da gestação e do puerpério, daí a ênfase na educação perinatal durante o curso de formação a que assisti.

A partir de informações providas pela MBE, de sua própria experiência (pessoal e profissional) e das experiências compartilhas por outras doulas, elas 
problematizam a maioria das justificativas médicas para a realização da cesárea, bem como as práticas rotineiras em torno do parto vaginal nos hospitais, tais como: i. aquelas requeridas para procedimentos cirúrgicos, como a lavagem intestinal e o jejum (que não deveriam ser realizadas na situação de parto vaginal); ii. aquelas que visam a acelerar o período expulsivo, como a episiotomia (incisão cirúrgica na musculatura perineal), a manobra de Kristeller (pressão forte sobre a barriga da mulher - técnica contraindicada pela OMS e pelo Ministério da Saúde), a amniotomia (ruptura artificial da bolsa amniótica) e a aplicação de ocitocina sintética (hormônio que pode acelerar ou regularizar as contrações uterinas); e iii. aquelas que se destinam a impedir que a mulher experimente a sensação de dor derivada das contrações uterinas. Questionam também a obrigatoriedade de a mulher ficar imóvel na posição horizontal, com as pernas abertas, e dos exames de toque sucessivos durante o trabalho de parto. Além disso, questionam o corte imediato do cordão umbilical e a separação do recém-nascido, por longo período, para a realização de procedimentos que são considerados desnecessários. Elas argumentam que várias dessas práticas estão em desacordo com as evidências científicas mais recentes e as recomendações da OMS.

É comum que essas práticas ocorram na forma de "efeito-cascata", assim, por exemplo, se a mulher é obrigada a ficar em jejum, é provável que sinta fome e sede ao longo do trabalho de parto; imobilizada na posição horizontal, as dores das contrações são mais intensas, o que pode levá-la a solicitar analgesia ou mesmo uma cesariana; se ela receber uma anestesia peridural, dificilmente conseguirá se concentrar no ritmo das contrações e fará força na hora errada, o que causa lacerações e dissipa as energias; para evitar a possível laceração e para acelerar o período expulsivo, o obstetra pode sugerir a amniotomia (que aumenta as chances de infecção) e a aplicação de ocitocina sintética; porém, se a dilatação não evolui conforme o esperado, ele pode fazer uma episiotomia, para abreviar o sofrimento da mulher (causado pelas intervenções, segundo elas) e evitar o "sofrimento fetal".

Durante a audiência pública sobre a "Lei do Parto Humanizado no DF", em novembro de 2016, duas doulas me disseram que a redução das taxas de cesariana, celebrada por uma das autoridades que falava ao microfone, não deve ser analisada como um fato isolado, posto que, em muitas situações, tal redução pode ocultar a prática de outras violências, tanto em termos de aumento de procedimentos invasivos, como maiores taxas de episiotomia e aplicação de ocitocina 
sintética, por exemplo, quanto em termos de negligência (não realização de cesariana intraparto, quando justificada por razões clínicas), a depender da vinculação institucional do hospital: "Mas é só a doula que percebe essas coisas", enfatizaram.

Ademais, no ciberespaço circulam relatos sobre as consequências da episiotomia, a saber: incontinência urinária e fecal, cicatriz de grandes dimensões, dores localizadas e prejuízos à vida sexual da mulher por anos. Alguns desses relatos fazem menção ao "ponto do marido", uma imagem empregada por alguns médicos para ressaltar aquilo que consideram um benefício da cirurgia para o homem, que assim teria novamente uma mulher "nova”, "apertada", em alusão à virgindade.

Sublinho que a atitude de problematizar tais procedimentos e condutas não consiste na recusa das práticas em si, mas expõe o fato de que elas são, muitas vezes, realizadas sem indicação clínica clara e sem o consentimento da parturiente, isto é, sem que informação científica "atualizada" e idiossincrasias da mulher atendida sejam levadas em consideração pelos profissionais.

De acordo com várias doulas, tais intervenções muitas vezes se somam a abusos ou atos de violência explícita. Com efeito, no conceito de "violência obstétrica" vigente nesse universo cabem: toda forma de ofensa, humilhação, constrangimento, coação, prestação de informações distorcidas ou incompletas, negativa de atendimento de qualidade, lesão corporal, tratamento aviltante, impedimento da entrada de acompanhante na sala de parto, desconsideração das opiniões e solicitações emitidas pela parturiente, esterilização não solicitada pela mulher, dentre outros. Para as instrutoras do curso de formação a que assisti, sobretudo para Marina, violência obstétrica é toda e qualquer prática "desatualizada”, isto é, não respaldada pela medicina baseada em evidências, que não respeita o protagonismo da mulher. Elas explicaram que a maioria das violências praticadas contra a mulher durante o momento do parto é justificada com o apelo à necessidade pungente de resguardar a saúde do bebê, por isso, em seus discursos, insistem na indissociabilidade do binômio "mãebebê", em nome da explicitação das violências e abusos praticados contra a mulher. ${ }^{22}$

Para fazer frente à violência obstétrica, essas mulheres apostam na "informação", concebida como fundamento do "empoderamento" da mulher perante o sistema médico-hospitalar e o senso comum, que consiste basicamente no conhecimento sobre os direitos previstos em lei e sobre dados médicos atualizados. "Empoderar" por meio da informação faz o oposto das táticas de "desem- 
poderamento" empregadas pelos profissionais de saúde desde o início da gestação, durante o acompanhamento pré-natal convencional, as quais produziriam infantilização e fragilização da mulher perante o sistema médico-hospitalar.

Grande parte dos enunciados correntes no universo da "humanização" do parto e apropriados pelas doulas alinhadas à MBE passa pelo crivo simbólico da ciência, assim como observado de modo mais geral por Davis-Floyd \& Sargent (1997:22). Mas o recurso à fisiologia, com destaque para os hormônios (especialmente a ocitocina), e aos "instintos" femininos me parece uma estratégia discursiva original para legitimar, em meio a um campo de disputas simbólicas, políticas e institucionais, um modo de pensar e agir diferenciado, marcadamente relacional (fundamentado no conceito de empatia/conexão/vinculamento) e holístico, que pode ser classificado como "tecnologia leve", conforme mencionado por Sônia.

Neste sentido, sugiro que, quando minhas interlocutoras empregam os qualificativos "instintivo", "fisiológico" ou "natural", o fazem de uma forma singular, visto que a suposta dimensão puramente orgânica ou fisiológica (não-mediada) do parto é refratada por um conjunto de saberes, técnicas e posicionamentos impregnados de significado, configurando-se uma agencialidade politizada, condensada no termo "sororidade".

\section{Considerações finais}

Gestado em meio ao estilo de vida individualista predominante nas camadas médias urbanas, tensionando, em alguma medida, a compreensão feminista clássica segundo a qual a maternidade é um fardo, o ideário da "humanização" do parto e do nascimento propõe que as experiências de parto, gestação e puerpério são únicas em sua complexidade e que devem ser respeitadas como tal. Esse entendimento se constrói como contraponto ao tratamento considerado "desumano", geralmente oferecido pela instituição médico-hospitalar, que consiste na banalização do parto e na violência que se expressa em palavras e práticas pautadas pela premissa da fragmentação da pessoa.

A doula é uma figura particularmente importante nesse contexto, visto que apoia a mulher em sua recusa a encenar o script da paciente (figura passiva, objeto impotente ou ser assexuado), driblando o poder disciplinar médico-hospitalar. Argumentei que as metáforas do jogo e da dança, aqui empregadas para abordar a relação de doulagem, nos ajudam a superar análises que se valem 
de binarismos estanques, pois, ao realçar a potência feminina para atravessar a gestação, o parto e o puerpério, o discurso das doulas parece se desenrolar no "entremeio que resta" (cf. Agamben, 2016) da oposição entre Natureza e Cultura, ou entre "tradicional" e "tecnológico", um discurso que se apresenta sob a forma de um projeto de vida e de saúde de pessoas que se esquivam de ser tratadas como produtos (ou subprodutos) da "linha de produção de bebês perfeitos" (Martin, 2006).

As doulas estariam simultaneamente desestabilizando a supremacia de certos conceitos e imagens hegemônicos e propondo a formulação de outros sentidos, outro tipo de tecnologia e outros "conhecimentos autoritativos" concernentes às experiências de gestação, parto e puerpério. Desse modo, as tendências liberais, individualistas e hedonistas presentes no ideário da "humanização" do parto, sintetizadas na categoria nativa de "empoderamento", são infletidas por uma modalidade de apoio que idealmente se estabelece no horizonte da sororidade.

Atravessada pela compreensão de minhas interlocutoras, entendo que "humano", no universo estudado, diz tanto (ou mais) sobre "instinto" quanto sobre "respeito" às necessidades, desejos, decisões e projetos da mulher, assumindo que a conduta respeitosa se refere a uma modalidade positiva de vinculamento, constituída por meio de pequenas escolhas cotidianas. Enfim, espero ter demonstrado que o alcance antropológico, ético, epistemológico e político desse trabalho de confecção de bons vinculamentos (sintetizado na expressão "mulheres que apoiam mulheres"), face a um projeto de uniformização e padronização de modos de estar no mundo, figura como um convite para novas pesquisas e reflexões.

Recebido: 31/12/2017

Aprovado: 17/04/2018

Giovana Tempesta é doutora em Antropologia Social pela UnB e atualmente realiza pesquisa sobre o papel das doulas no interior do movimento de "humanização" do parto no Brasil. No Mestrado, pesquisou as práticas de resguardo de parto e menstruação entre os povos indígenas Wapichana e Macuxi, em Roraima. No Doutorado, estudou a etno-história e a organização sociopolítica do povo Apiaká, que vive no Mato Grosso. Seus temas de interesse são: 
corporalidade, noção de pessoa, concepções locais de saúde e cuidado e modos de criação de sociabilidade. Contato: giovana.tempesta@gmail.com

\section{Notas}

1. As interlocutoras mencionadas no presente artigo são doulas e educadoras perinatais, porém, por comodidade de exposição, eu me refiro a elas na maioria das vezes somente como doulas. A educação perinatal é um processo de preparação da gestante (e, por vezes, também de seu companheiro ou companheira) para as experiências de gestação, parto e puerpério, e abrange os seguintes tópicos: fases da gestação, fisiologia do parto, tipos e locais de parto, sexualidade, desenvolvimento do bebê, amamentação, cuidados com o bebê, dentre outros conexos.

2. Algumas ideias aqui desenvolvidas foram apresentadas no Simpósio Temático 91 - Maternidades, movimentos de mulheres e feminismos do $13 .^{\circ}$ Mundo de Mulheres \& Fazendo Gênero 11, realizado em Florianópolis, em agosto de 2017. Gostaria de deixar registrada minha gratidão a Rosamaria Giatti Carneiro, Soraya Fleischer, Sílvia Guimarães, Aline Silveira, Mariana Marques Pulhez, Patrícia Mendonça Rodrigues e Valéria de Paula Martins, que leram versões iniciais deste artigo, bem como a Paloma Terra, que fez a ponte com as doulas que aceitaram dialogar comigo e que tanto me ensinaram, mas cujos nomes serão mantidos em anonimato, de modo a proteger sua privacidade. Todavia, sublinho que a responsabilidade pelas ideias aqui apresentadas é inteiramente minha.

3. A própria expressão "parto humanizado" não é empregada de modo recorrente pelas minhas interlocutoras, sendo que uma delas chega a afirmar, explicitamente, que prefere utilizar a expressão "parto respeitoso", para marcar posição em relação ao que chama de "produto", referindo-se a um nicho de mercado em expansão, que agrega profissionais “que se vendem como humanizados", mas que nem sempre são efetivamente respeitosos em sua prática.

4. Participei da 32. ${ }^{a}$ edição deste que é um curso de projeção nacional, no qual já foram formadas cerca de mil mulheres. O módulo básico é composto de 120 horas e abrange uma parte teórica, demonstração de técnicas para alívio de dor e desconforto, atividades em grupo, exibição de documentários, momentos de reflexão individual, rodas de conversa e "vivências". O valor do curso corresponde a aproximadamente um salário mínimo e meio.

5. Esclareço que os dados etnográficos estão registrados em diário de campo, que todos os nomes aqui citados são fictícios e que o projeto de pesquisa foi analisado e 
aprovado pelo Comitê de Ética em Pesquisa em Ciências Humanas e Sociais (CEP/ CHS) da Universidade de Brasília.

6. O termo "técnica" está sendo empregado em seu sentido corrente, como uma habilidade especial para fazer algo, no caso, as habilidades para realizar procedimentos destinados a amenizar desconfortos e dores ao longo da gestação, do parto e do puerpério, bem como para prover informações baseadas em evidências científicas atualizadas, visando o bem-estar da mulher. Mais adiante aparecerá a expressão "tecnologia leve”, empregada por algumas de minhas interlocutoras para qualificar seu ofício em certos círculos sociais.

7. Os endereços eletrônicos são, respectivamente: <http: / /www.amigasdoparto. com.br/>, <http: / /www.partodoprincipio.com.br/> e <https: / /www.facebook. $\mathrm{com} /$ orenascimentodoparto/ $>$.

8. Imagens desse ideário têm sido amplamente divulgadas como, por exemplo, no documentário O Renascimento do Parto, lançado em 2013 e produzido de forma independente por uma doula e um cineasta brasileiros, e na exposição Sentidos do Nascer, apoiada pelo CNPq e pelo Ministério da Saúde, que no ano de 2015 percorreu várias capitais brasileiras.

9. Para Latour: "A nova questão não se direciona ao sujeito, a sua autonomia, ao seu ideal de emancipação, assim como ela também não se direciona à objetivação ou à reificação que nos faria perder nossa autonomia: ela nos obriga a considerar a natureza precisa daquilo que nos faz ser. Se não se trata mais de opor vinculamento e desvinculamento, mas bons e maus vínculos, não há mais do que um meio para decidir a qualidade desses laços: perguntar-se o que eles são, o que fazem, aprender a ser afetado por eles" (Latour, 2016:70-71).

10. Para Agamben, o conceito deleuziano de "linha de fuga" permite pensar "uma fuga que não implica uma evasão: um movimento na situação em que ele acontece. Somente assim é que a fuga poderia ter uma significação política” (Agamben, 2016:20).

11. De acordo com Carneiro (2015), as adeptas do parto "humanizado" estão criando, a partir de referências forjadas no processo de "orientalização do ocidente", tal como apropriado pela contracultura e pelo movimento hippie nos anos 1960, uma nova cultura do nascimento no Brasil, por meio da ressignificação de conceitos como saúde, domesticidade, pureza/impureza, sagrado/profano, corpo, pessoa, cuidado, feminino, amor materno, fragilidade, dor e medo, e assim instaurando novos modos de subjetivação feminina, materna e feminista. Por seu turno, Tempesta (no prelo) identificou a metáfora da dança na análise de um relato de parto domiciliar planejado. 
12. Em 2015 a OMS divulgou uma declaração sobre taxas de cesárea no mundo, na qual o Brasil figurava como líder mundial, fenômeno qualificado de "epidemia" (Disponível em: <http: / /www.unasus.gov.br/noticia/declaracao-da-oms-sobre-taxas-de-cesareas $>$. Acesso em 1. ${ }^{\circ}$ nov. 2016. O inquérito nacional coordenado pela Fiocruz entre 2011 e 2012, intitulado Nascer no Brasil, demonstrou que a assistência ao parto é focada na decisão do médico, e não na dinâmica do corpo da mulher, resultando numa cifra alarmante de cesarianas, e que as mulheres de todos os segmentos socioeconômicos estão sendo desnecessariamente expostas à iatrogenia (problema de saúde decorrente de assistência médica, dentre as quais se destaca a depressão pós-parto) (Leal et al., 2014). A interseccionalidade de classe e raça nesse universo certamente merece uma reflexão aprofundada, a ser realizada em outra oportunidade.

13. "Sororidade" é um conceito corrente em círculos feministas. De acordo com o dicionário Priberam, significa: "relação de união, de afeição ou de amizade entre mulheres, semelhante à que idealmente haveria entre irmãs; união de mulheres com o mesmo fim”.

14. No último dia 8 de junho de 2018, foi publicada no Diário Oficial do Distrito Federal a Lei n. ${ }^{\circ} 6.144$, que "dispõe sobre a implantação de medidas de informação a mulheres grávidas e paridas sobre a política nacional de atenção obstétrica e neonatal, visando, principalmente, à proteção delas no cuidado da atenção obstétrica no Distrito Federal”; nessa lei, a definição de "violência obstétrica" é apresentada de forma abrangente. Vale sublinhar que a Associação de Doulas do Distrito Federal teve participação importante no processo de elaboração e aprovação dessa lei.

15. Esta é a tradução de S. Diniz (2005) para a expressão authoritative knowledge, elaborada por Brigitte Jordan em 1993 e retomada na coletânea organizada por Davis-Floyd \& Sargent, 1997 (Jordan, 1997).

16. Para uma reflexão preliminar sobre a polissemia das dores envolvidas no parto, ver Carneiro \& Tempesta (2018).

17. Para C. Lefort: "O próprio de uma sociedade "histórica”, segundo nos parece, é que ela contém o princípio do acontecimento e tem o poder de convertê-lo em momento de uma experiência, de modo que ele figura um elemento de um debate que se processa entre os homens. Deste modo, nela a transformação não é a passagem de um estado para outro, mas o encaminhamento deste debate que antecipa o futuro referindo-o ao passado. O que significa ainda dizer que o histórico não reside no acontecimento enquanto tal ou na transformação enquanto tal, mas em um estilo das relações sociais e das condutas em virtude do qual há colocação em jogo do sentido” 
(Lefort, 1978:47).

18. O documentário foi produzido pela equipe da UnBTV e dirigido por Barbara Arato; disponível em: <https: / / www.youtube.com/watch? $=$ DlUpSB6nr9c $>$. Acesso em: 26 set. 2017.

19. M. Portella (2017) faz uma análise minuciosa da hierarquia profissional em torno da qual se estrutura a assistência obstétrica na cidade de Recife (PE), inserindo-a no processo histórico de colonialidade dos saberes. A autora destaca o caráter híbrido da figura da doula, simultaneamente vinculada a uma ideia de saberes ancestrais femininos e à medicina baseada em evidências, assim como a horizontalidade na relação entre doula e parturiente e entre doula e outros profissionais na cena de parto. Ela trata ainda de situações de silenciamento e rebaixamento vividas por doulas no contexto hospitalar.

20. Com o termo "idealmente" desejo sublinhar que se trata de expectativas e objetivos declarados, de um conteúdo proposto pelas doulas, sem a intenção de camuflar casos esporádicos de doulas que tratam a cliente de forma desrespeitosa ou antiética.

21. Fazem parte do repertório de referências das doulas alinhadas à MBE escritos, registros audiovisuais, palestras e postagens na internet das doula Fadynha e Debra Pascali-Bonaro, das antropólogas Brigitte Jordan, Robbie Davis-Floyd e Sheila Kitzinger, da psicóloga Laura Gutman, das parteiras Ina May Gaskin e Elisabeth Davis, dos médicos Mardsen Wagner, Frédérick Leboyer, Michel Odent, José Galba Araújo, Moysés Paciornik, Jorge Kuhn, Ricardo Jones e da epidemiologista Daphne Rattner, dentre outros.

22. Por meio de um blog, Ligia Moreiras Sena (2016) analisou um conjunto significativo de relatos de mulheres sobre experiências de violência obstétrica à luz do referencial teórico-metodológico da saúde coletiva.

\section{Referências bibliográficas}

AGAmBEN, G. 2016. Uma Biopolítica Menor. Série Pandemia. N -1 Edições. (entrevista realizada por S. Grelet e M. Potte-Bonneville, originalmente publicada em Vacarme, vol. 10, jan/2000).

CARNEIRO, R. G. \& TEMPESTA, G. A. 2018. Para atravessar o portal da dor. Reflexões antropológicas sobre as diferentes dores associadas ao parto. Paper apresentado no GT 03 da II Reunião de Antropologia da Saúde, Brasília. Disponível em: <https: / / docs. wixstatic.com/ugd/d094b6_5d64f133f44b424d8c6726ae7f4a89d8.pdf>. Acesso em: 08 out. 2017. 
CARnEIRO, R. G. 2015. Cenas de Parto e Políticas do Corpo. Rio de Janeiro: Editora Fiocruz.

2014. De perto e de longe do que seria natural, mais natural e/ou humanizado. Uma etnografia de grupos de preparo para o parto. In: FERREIRA, J. \& FLEISCHER, S. (orgs.) Etnografias em Serviços de Saúde. Rio de Janeiro: Garamond. pp. 243-265.

CASTELLO, C. C. S. 2016. A doulagem como um “divisor de águas”: uma etnografia do curso de formação de doulas e educadoras perinatais da Matriusca. Monografia de Graduação, Brasília: Universidade de Brasília.

DAVIS-FLOYD, R. E. \& SARGENT, C. F. 1997. Introduction. The Anthropology of Birth. In: (eds.) Childbirth and Authoritative Knowledge. Cross-cultural perspectives. Berkeley, Los Angeles, London: University of California Press, pp. 1-51.

DAVIS-FLOYD, R. E \& DAVIS, E. 1997. Intuition as authoritative knowledge in midwifery and home birth. In: DAVIS-FLOYD, R. E. \& SARGENT, C. F. (eds.) Childbirth and Authoritative Knowledge. Cross-cultural perspectives. Berkeley, Los Angeles, London: University of California Press. pp. 315-349.

DESLANDES, S. F. (org.) 2006. Humanização dos Cuidados em Saúde: conceitos, dilemas e práticas. Rio de Janeiro: Editora Fiocruz. 3. ${ }^{a}$ reimpressão

DINIZ, S. G. 2005. Humanização da assistência ao parto no Brasil: os muitos sentidos de um movimento. Ciência e Saúde Coletiva, 10 (3): 627-637.

FADYNHA. 2011. A Doula no Parto. O papel da acompanhante de parto especialmente treinada para oferecer apoio contínuo físico e emocional à parturiente. 3. a ed. São Paulo: Ground.

FLEISCHER, S. 2005. Doulas como “amortecedores afetivos”. Notas etnográficas sobre uma nova acompanhante de parto. Revista Ciências Sociais da Unisinos, 41 (1): 11-22.

HIRSCH, O. 2014. O parto "natural" " "humanizado": um estudo comparativo entre mulheres de camadas populares e médias no Rio de Janeiro. Tese de Doutorado, Rio de Janeiro: Pontifícia Universidade Católica do Rio de Janeiro.

JORDAN, B. 1997. Authoritative knowledge and its construction. In: DAVIS-FLOYD, R. E. \& SARGENT, C. F. (eds.) Childbirth and Authoritative Knowledge. Cross-cultural perspectives. Berkeley, Los Angeles, London: University of California Press. pp. 55-79.

LATOUR, B. 2016. Faturas/fraturas: da noção de rede à noção de vínculo. In: SEGATA, J. \& RIFIOTIS, T. (orgs.) Políticas Etnográficas no Campo da Cibercultura. Brasí- 
lia: ABA Publicações; Joinville: Editora Letradágua.

LEAL, M. C. et al. 2014. Intervenções obstétricas durante o trabalho de parto e parto em mulheres brasileiras de risco habitual. In: Cadernos de Saúde Pública, 30 (1) (Disponível em: <http://www.scielo.br/scielo.php?script=sci_arttext\&pi$\mathrm{d}=$ S0102-311X2014001300005\&lng=pt\&nrm=iso\&tlng=pt\#B1>. Acesso em: 03 out. 2017).

LEFORT, C. 1978. As Formas da História: ensaios de antropologia política. São Paulo: Brasiliense.

LÉVI-STRAUSS, C. (1958) 1970. A Análise Estrutural em Linguística e em Antropologia. In: Antropologia Estrutural. 2. ${ }^{a}$ edição. Rio de Janeiro: Tempo Brasileiro. pp. 47-71.

LOUREIRO, F. 2017. Sobre "a porta que abre por dentro": análise cultural do processo de formação de doulas para a assistência ao parto no Brasil. Dissertação de Mestrado, Rio de Janeiro: Universidade do Estado do Rio de Janeiro.

MARTIN, E. 2006. A mulher no corpo. Uma análise cultural da reprodução. Rio de Janeiro: Garamond.

MATTINGLY, Cheryl. 2014. Moral Laboratories. Family peril and the struggle for a good life. Oakland: University of California Press.

PIMENTEL, C. et al. 2014. Autonomia, Risco e Sexualidade. A humanização do parto como possibilidade de redefinições descoloniais acerca da noção de sujeito. REALIS, 4 (1): 166-185.

PORTELLA, M. O. 2017. Ciência e costume na assistência ao parto. Tese de Doutorado, Recife: Universidade Federal de Pernambuco.

PULHEZ, M. M. 2015. Mulheres Mamíferas: práticas da maternidade ativa. Dissertação de Mestrado, Campinas: Universidade Estadual de Campinas.

RODRIGUES, L. O. 2015. Parir é libertário. Etnografia de um grupo de apoio ao parto humanizado de Recife/PE. Tese de Doutorado, Recife: Universidade Federal de Pernambuco.

SALEM, T. 2007. O Casal Grávido. Disposições e dilemas da parceria igualitária. Rio de Janeiro: FGV Editora.

SENA, L. M. 2016. “Ameaçada e sem voz, como num campo de concentração”. A medicalização do parto como porta e palco para a violência obstétrica. Tese de Doutorado, Florianópolis: Universidade Federal de Santa Catarina.

SOUZA, H. R. 2005. A arte de nascer em casa: um olhar antropológico sobre a ética, a estética e a sociabilidade no parto domiciliar contemporâneo. Dissertação de Mestrado, Flo- 
rianópolis: Universidade Federal de Santa Catarina.

STRAUS, S. \& McALISTER, F. 2000. Evidence-based medicine: a commentary on common criticisms. CMAJ/JAMC, 163 (7): 837-841.

TEMPESTA, G. A. No prelo. Contestações ritmadas. Notas sobre o simbolismo do útero presente em relatos de parto. . 2017. Sobre laboratórios e jardins. Resenha de Moral Laboratories. Family peril and the struggle for a good life. Revista de Antropologia (São Paulo, Online), 60 (2): 647-652.

TORNQUIST, C. S. 2004. Parto e Poder. O movimento pela humanização do parto no Brasil. Tese de Doutorado, Florianópolis: Universidade Federal de Santa Catarina. 2002. Armadilhas da nova era: natureza e maternidade no ideário da humanização do parto. Revista Estudos Feministas, 10 (2): 483-492. 
Resumo: $\mathrm{O}$ artigo trata de um aspecto central do trabalho realizado pelas doulas e educadoras perinatais - profissionais que prestam apoio físico, emocional e informacional à mulher durante a gestação, o parto e o puerpério -, qual seja, a habilidade de estabelecer e sustentar um certo tipo de vinculamento com a mulher. A partir da pesquisa com doulas alinhadas à medicina baseada em evidências científicas que atuam em Brasília (DF), proponho que certos conceitos, imagens e afetos mobilizados por elas tensionam e desafiam a hegemonia dos valores que sustentam os protocolos adotados pelas instituições médico-hospitalares. O conceito de vinculamento (Latour, 2016) nos ajuda a perceber que, sob o aparente contrassenso de uma pedagogia do instinto feminino aplicada pelas doulas, viceja uma modalidade diferencial de cuidado, que pode ser condensada na expressão "mulheres que apoiam mulheres", e que, em alguma medida, desestabiliza as tendências liberais, individualistas e hedonistas presentes no ideário da "humanização" do parto.

Palavras-chave: parto, humanização, doula, vinculamento
Abstract: The article deals with a central aspect of the work performed by doulas and perinatal educators - professionals who provide physical, emotional and informational support to women during pregnancy, childbirth and the puerperium - that is, the ability to establish and sustain a certain type of relationship with women. From the research with doulas aligned to scientific evidence-based medicine in Brasília (DF), I propose that certain concepts, images and affections mobilized by them stress and challenge the hegemony of the values that support the protocols adopted by the medical institutions. The concept of bonding (Latour, 2016) helps us to perceive that under the apparent contradiction of a female instinct pedagogy applied by the doulas, there is a differential modality of care, which can be condensed into the expression "women who support women", and which to some extent destabilizes the liberal, individualistic and hedonistic tendencies present in the ideology of the "humanization" of childbirth.

Keywords: childbirth, humanization, doula, bonding 